\title{
Research of Multi-level Inverter in PVMS of Micro-grid
}

\author{
WANG Gen ping \\ Department of Mechanical \& Electricity \\ Shenzhen Polytechnic \\ Guangdong Shenzhen, 518055, China \\ fwgp@yahoo.com
}

\author{
TAN Yu mei, YI Ling zhi \\ College of Information Engineering \\ Xiangtan University \\ Hunan Xiangtan ,411105, China \\ ylzwyh@sohu.com
}

\begin{abstract}
The research of control and protection in Microgrid technology is key to distributed generation(DG), such as wind power, Photovoltaic (PV) power generation, tidal power and so on. Through DC-AC converter or AC-DC-AC converter the renewable energy supply power to the loads, so the power electronics technology has a decisive role in DG and Microgrid technology based on renewable energy. In this paper, the problems of traditional Photovoltaic micro-source (PVMS) power generation is firstly listed, then the reason of maximize efficiency when a number of PV arrays in series connection with traditional two-level inverter is analyzed, a PV Micro-grid control strategy based on multi-level diode-clamped inverter will be proposed. The reliability and superiority of PVMS using in multi-level inverter will be testified on simulation.

Keywords- Micro-grid; distributed generation; Photovoltaic micro-source; multi-level
\end{abstract}

\section{INTRODUCTION}

Energy issue has become a serious challenge among world countries, While the aging of power system structure, environmental problems, and the bottleneck of efficiency to energy using and high standards to power quality, which allowing the exploitation to renewable energy and structuring sustainable energy system has become a consensus and consequently development trend in recent years. DG could be a digestive power locally, transmission investment and operation cost could also be saved, the line loss of concentrated transmission is reduced; complementing with the supply of large power system, there are many advantages, such as reducing power capacity, improving the performance of power peak and valley, increasing reliability of power supply and reducing the environment, etc. It made DG has been widely concerned, particularly PV and wind power generation system has been rapidly developed in recent years ${ }^{[1-2]}$. With growing number of PV power stations are installed; the potential development technology of PV conversion and the reduction in generation cost per watt will bring large-scale industrial development to $\mathrm{PV}$ power generation $^{[3]}$.

To solve the question of DG itself ${ }^{[4]}$, such as high cost of access to distributed power, randomness to power output of some distributed power, etc. The large-scale system tends to adopt restrict and isolated way to handle distributed power which could reduce its impact on the bulk power system. For the coordination of power system and distributed generation, fully exploit the value and benefits which supplied by distributed generation, further improve flexibility, controllability and economy of power system operation, a form which could preferably develop the potential of distributed generation. Micro Source(MS) is small power plants (less than $100 \mathrm{kw}$ ) containing of power electronic devices, which including wind generators, micro turbines, fuel cells, PV cells, as well as super capacitors, flywheels, batteries and other energy storing devices ${ }^{[5-6]}$.

The conventional generating is electric energy of some $\mathrm{MS}$ is more than the power frequency, such as micro turbine, some are generate DC directly, such as fuel cells and PV cells, due to the normal load are power frequency electric load, connected with Micro-grid system need to pass through the power electronic converter to load, which requires a relatively high standard to power electronics technology. These converters may include both rectifier and inverter, or only include a inverter. Converter owns the identities of high speed, low inertia and inferior over-current capability, which makes the control concept of Micro-grid's energy management, is very different from the conventional system. Thus, the control of inverter has been become an important aspect of MS research.

In PV power generation system, a series of PV arrays are connected in conventional two-level inverter, some problems of shaded and mismatching in PV arrays will occur, which cause the power-generating capacity can not be maximized. To solve these problems, a project of connecting PV array(PVA) to the diode-clamped multi-level converter is provided in this paper. Pulse width modulation is used to control each operating voltage of the PVA independently. Compared with traditional two-level inverter system, it allows maximum power of PV Micro-grid output and reduces rated voltage of equipment, the performance of device becomes better, the distortion of PV Micro-grid output voltage can be reduced, the system efficiency can be increased.

\section{TRADITIONAL TWO-LEVEL INVERTER}

\section{A. MS technology in PV power generation}

Micro-grid integrates the advantages of $\mathrm{DG}$, reduces the impact and negative results of DG to the power grid, and then a new distributed energy organization and structure is proposed. Micro-grid is closely integrated with wind power, solar, biomass, micro turbines and other power supply; it is distributed near the center of the user load which mitigates the impact on the environment, reduces the burden of large 
scale power system and improves reliability and security of power supply. Micro-grid has already caused a high degree of concern among developed countries such as the United States, Europe and Japan, and its gives a large number of input and support. PV power generation Micro-grid system has the excellence of clean, low operation cost, can be distributed near the user load center directly and appropriate for urbanization application, etc. therefore, it will become an important technical way of distributed renewable energy generation and power grid.

Schematic diagram of the Micro-grid see Figure.1,it consists of PV cells, a wind generators, fuel cells, power conversion devices, energy storing devices(capacitor, flywheel, battery), controller and load. When switch KA closed, the Micro-grid is in running, when open, it comes into island run.

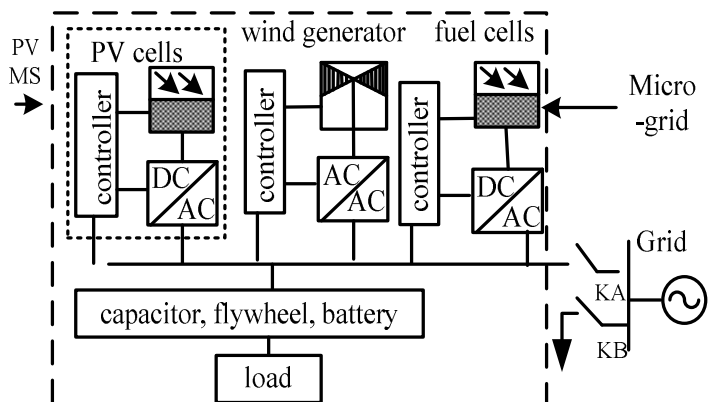

Figure.1 Schematic diagram of Micro-grid.

\section{B. Problems}

In PV power generation MS, one or more PV arrays through the way of series or paralleling is used, then transform solar energy into DC power energy, so various forms of electrical energy for the load use are transformed through the power electronic converters. PV arrays act as the basic unit of solar power generation are susceptible to the surrounding buildings, trees, telegraph poles, as well as dark clouds, which result in deterioration of arrays identities, the ability of output power is reduced, and even forms hot spots, damages PV arrays, lastly the Micro-grid power capacity will be greatly depressed so that affect the power generation efficiency.

In Figure.2(a), the I-V characteristic (shown in dotted lines) of two PV cells under two different irradiance levels. The I-V characteristic of the small PV string is represented by solid line through a series connection of PV arrays. In Figure.2(b), P-V characteristic that each individual PV arrays are in series, with dotted line and solid line. There are two peaks of P-V characteristic under the conditions of nonuniform irradiation in Figure.2, under the application of maximum power point tracking technology [7], it will converter to a local maximum, and this maximum is not the maximum power point in series ${ }^{[8]}$.

Traditional two-level three-phase inverter converts DC power generated by $\mathrm{PV}$ arrays into $\mathrm{AC}$, see Figure.3. The panel is consisted by $\mathrm{n}-1$ series-connected PV arrays, in series connection, the same current must flow through all
PV arrays, at the same time, so that the system can not control every single operating voltage of PVA separately, resulting in acquired energy can not be maximized.

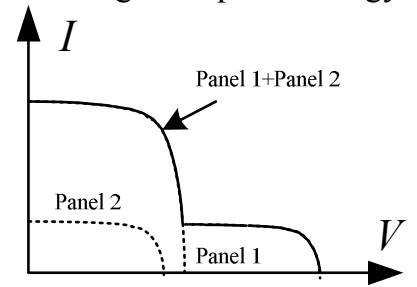

(a) Characteristics of I-V (b) Characteristics of Output P-V

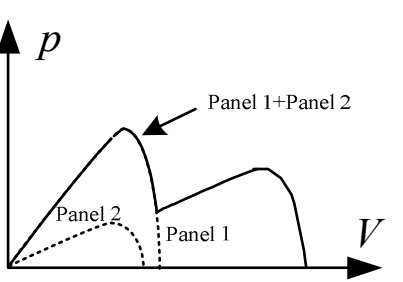
Figure.2 Characteristics of String Modules under Different Solar Irradiance Level

To solve this problem, some authors proposed to add some extra circuitry which each PVA will be presented different current value $^{[9]}$, therefore, each PVA voltage can be controlled at maximum power point independently, the power generated by the system will greatly improved ${ }^{[10]}$, but it will also increase the cost of system and lower the utilization of system. A control methods that using multi-level diode-clamped inverter instead of traditional two-level inverter is presented in this paper, see Figure.3, the multi-level inverters own more advantages besides of obtaining the maximum energy for PVA, such as reducing the voltage stress of devices, so the higher efficiency can be got which produce an $\mathrm{AC}$ voltage featuring low harmonic distortion.

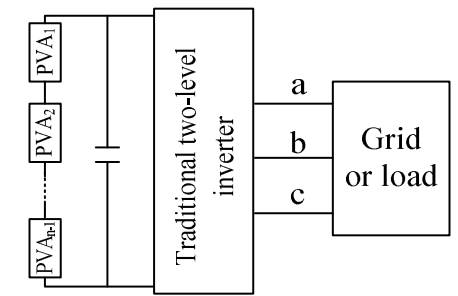

Figure.3 Traditional Two-level Inverter structure

\section{MODULATION OF MULTI-LEVEL INVERTER}

AC voltage is synthesized by multi-level inverter technology which is based on a number of different voltage level of its DC side, if the number is increased, the AC output waveform is formed by more levels and that not only the waveform is closer to the sine wave but also the harmonic content is getting lower and lower, reducing the need for filters significantly, and furthermore, it is more efficient due to the switching devices of multi-level inverter are working under the fundamental frequency. Figure.4(a) is the control diagram of Photovoltaic Micro-Source based on multi-level diode-clamped inverter, the structure of control and modulation principles are proposed. And the functions of several main modules are showed.

\section{A. Modulation block}

The modulation block can generate the phase duty-ratio variables from the information of reference vector length (m) and angle $(\theta)$. Modulation strategy can be used to this block as proposed in [11]. The modulation strategy will ensure low-frequency interference not generate in the three- 
phase output voltage even work under the unequal PVA voltage for the midpoint voltage have been effectively controlled.

\section{B. Unblanced control block}

Figure.4(a) will be simplified as shown in Figure.4(b), for each internal DC link point $j(j=2,3, \cdots, n-1)$, two partial DC link voltages are defined:

$$
v_{j 1}=\sum_{k=1}^{j-1} v_{P V A K} \quad v_{n j}=\sum_{k=j}^{n-1} v_{P V A K}
$$

The correspondingly average voltage is:

$$
\bar{v}_{j 1}=\frac{\sum_{k=1}^{j-1} v_{P V A K}}{j-1}, \bar{v}_{n j}=\frac{\sum_{k=j}^{n-1} v_{P V A K}}{n-j}
$$

For each internal DC voltage point $\mathrm{j}$, the difference between the corresponding normalized sensed partial voltage is computed firstly, then the same difference for the command values is computed, and the variable $P_{i}$, which indicates the required control effect is obtained, extracting or injecting current from or into DC link point $\mathrm{j}$, to achieve the desired partial voltage unbalance. Through the combination control of modulator block and unbalance control block, the actual operating voltage of every PVA can be ensure equal to the corresponding control voltage, thus the PV power generation system is always ensure work at maximum power point.

The ideal control voltage value can be obtained through the MPPT algorithm ${ }^{[12-13]}$. By collecting the two-phase currents and two line-to-line voltages, and MPPT control algorithm is used simultaneously, thus the voltage at MPP can be got which is the ideal control voltage ${ }^{[14-15]}$.
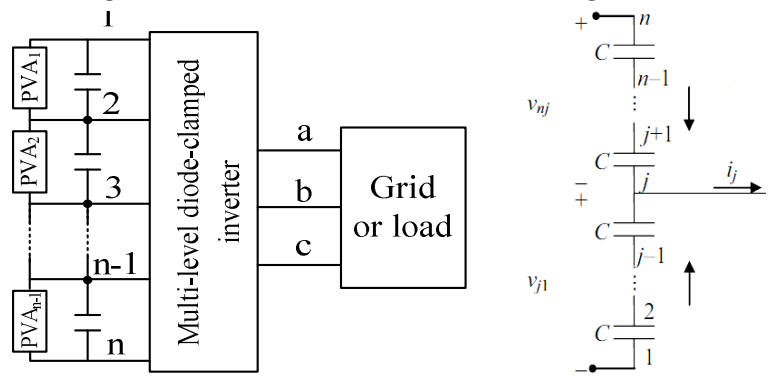

(a) Diode-clamped multi-level Inverter (b) Node Map of Multi-level Inverter DC side Figure.4 Multi-level Inverter

\section{Duty-ratio-perturbation control block}

When the duty-ratio waveform perturbation is turned up, a closed-loop control strategy have been proposed to ensure the voltage balance, this strategy can be used in any number of level and any basic modulation types of multi-level inverter. The duty-ratio perturbation control block is responsible for modifying the generated duty-ratio, to reduce the error between them when the detection voltage is different with control voltage. Assuming $i_{a}+i_{b}+i_{c}=0$, the control algorithms are as follows:

$$
\begin{aligned}
& \text { pow }=i_{a} \cdot v_{a c}+i_{b} \cdot v_{b c} \\
& \text { if }\left(p_{j} \cdot \text { pow } \geq 0\right)\{ \\
& \text { if }\left(d_{x n}>\left|p_{j}\right| /(n-j)\right)\{ \\
& d_{x n}{ }^{\prime}=d_{x n}-\left|p_{j}\right| /(n-j) \\
& d^{\prime}{ }_{x 1}=d_{x 1} \\
& \text { \}else }\{ \\
& d_{x n}^{\prime}=0 \\
& d_{x 1}^{\prime}=d_{x 1}+\left[\left|p_{j}\right| /(n-j)-d_{x n}\right] \cdot[(n-j) /(j-1)] \\
& \text { \} } \\
& \text { \}else \{ } \\
& \text { if }\left(d_{x 1}>\left|p_{j}\right| /(j-1)\right)\{ \\
& d_{x 1}^{\prime}=d_{x 1}-\left|p_{j}\right| /(j-1) \\
& d^{\prime}{ }_{x n}=d_{x n} \\
& \text { \}else }\{ \\
& d^{\prime}{ }_{x 1}=0 \\
& d^{\prime}{ }_{x n}=d_{x n}+\left[\left|p_{j}\right| /(j-1)-d_{x 1}\right] \cdot[(j-1) /(n-j)] \\
& \} \\
& \text { \} } \\
& d_{x j}^{\prime}=\left(d_{x 1}+d_{x j}+d_{x n}\right)-d^{\prime}{ }_{x 1}-d^{\prime}{ }_{x n}
\end{aligned}
$$

The error $P_{i}$ generated by unbalanced control block is input into the duty-ratio perturbation control block with the dutyratio generated by modulation simultaneously, the resulting modified phase duty-ratios $\left(d^{\prime}{ }_{x l}, \cdots, d^{\prime}{ }_{x n}\right)$ are symmetrically distribute the connections of each phase to each of the DC link points within a switching cycle and generate the switch control signals.

\section{SimUlation}

Simulation can be easily carried out by using MATLAB in accordance with the principle process, Simulate to the PVMS adopted by the two series of PVA formed after threelevel diode-clamped inverter. Take diode-clamped threelevel Inverter to Simulation, the topological structure of diode-clamped three-level Inverter see Figure.5, the results are shown in Figure. 6 and Figure.7 under two different conditions, which show the simulation results of steadystate output voltage and current when the two PVA voltages are equal and unequal.

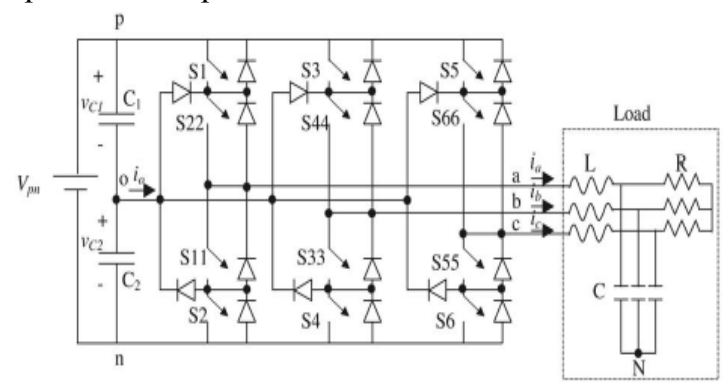

Figure.5 Topological structure of Diode-clamped three-level Inverter 

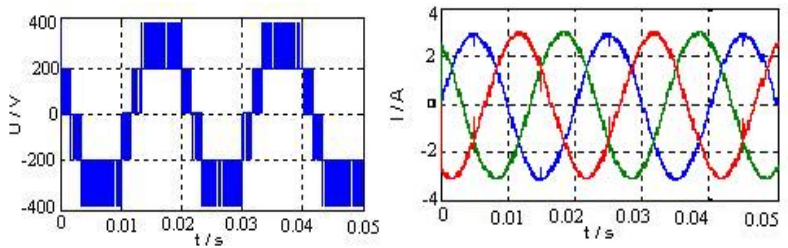

(a) Line output voltage waveform (b) Output current waveform Fundamental $(50 \mathrm{~Hz})=2.995, \mathrm{THD}=0.23 \%$

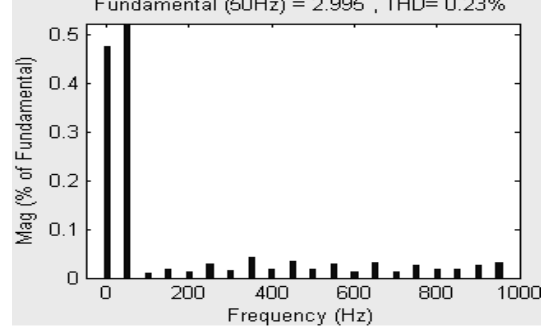

(c) Harmonic analysis of the current

Figure.6 Simulation results $\left(\mathrm{v}_{\text {PVA1 }}^{*}, \mathrm{v}_{\text {PVA2 }}^{*}\right)=(200,200) \mathrm{V}$
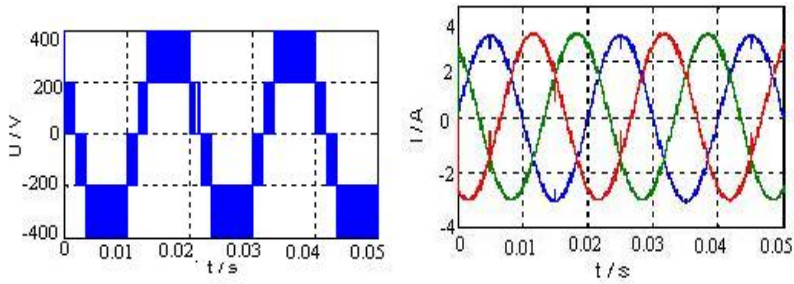

(a) Line output voltage waveform (b) Output current waveform

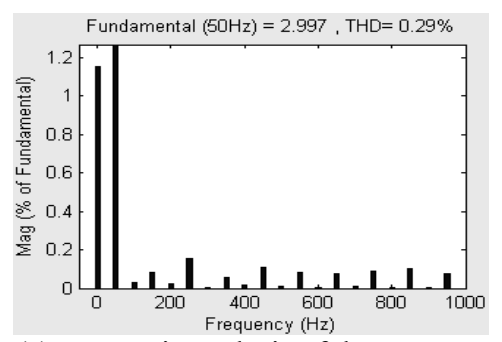

(c) Harmonic analysis of the current

Figure.7 Simulation results $\left(\mathrm{v}^{*}{ }_{\mathrm{PVA} 1}, \mathrm{~V}_{\mathrm{PVA} 2}^{*}\right)=(180,220) \mathrm{V}$

Simulation results show that even in the circumstances that the PVA voltage is different, the PVA voltage is also used to synthesize the output voltage, and the result is almost the same with PVA voltage, furthermore, the harmonic distortion is lowed down, so output power quality of PVMS is greatly improved, and in three-level inverter, the total output power can be increased to $132 \%$ by the use of unbalance controller.

\section{CONCLUSION}

In this paper A new unbalance control strategy of PVMS based on multi-level inverter is presented, and the control and modulation scheme to connect PVA and threephase multi-level diode-clamped inverter is improved too. This program allows setting the maximum power point voltage of PVA independently without reducing the quality of the output voltage. Compared with the traditional twolevel inverter system, especially under the shaded part of the
PV devices or mismatching of PVA, the PVMS output power is effectively increased in this system. In addition, the device's rated voltage is debased by the application of multilevel diode-clamped inverter, which allowing increase the operating voltage without the use of transformers, thus the output harmonic distortion of PVMS is reduced and the efficiency of power conversion is increased.

\section{ACKNOWLEDGMENT}

This work is supported by National Nature Science Foundation under Grant 50977080, the project of Hunan province Science \& Technology Department 2010FJ3116 and Hunan province education department 10A114.

\section{REFERENCES}

[1] Katiraei F, Iravani M R. Power Management Strategies for a Microgrid With Multiple Distributed Generation Units [J]. IEEE Transactions on Power Systems, 2006, 21 (4):1821-1831.

[2] Lasseter $\mathrm{R} \mathrm{H}$. The role of distributed energy resources in future electric power systems[C]. Energy Systems Seminar, University of Wisconsin,2006.

[3] WANG Zhiqun, ZHU Shouzhen,ZHOU Shuangxi . Impacts of distributed generation on distribution system voltage profile [J]. Automation of Electric Power Systems, 2004, 28(16):56-60.

[4] S. B. Kjaer, J. K. Pedersen, and F. Blaabjerg, "A review of singlephase grid-connected inverters for photovoltaic modules," IEEE Trans. Ind. Appl., vol. 41, no. 5, pp. 1292-1306, Sep./Oct. 2005.

[5] BAI Qian, LI Peng. Voltage regulation based on allocation optimization of distributed generation and SVG [J].Electric Power Automation Equipment, 2007, 27(7):62-65.

[6] WANG Cheng-shan, CHEN Kai, XIE Ying-hua, ZHENG Hai-feng. Siting and Sizing of Distributed Generation in Distribution Network Expansion Planning [J]. Automation of Electric Power Systems, 2006,30(3):38-41.

[7] ZHANG Chao, HE Xiang-ning. Short-current combined with perturbation and observation maximum-power-point tracking method for photovoltaic power systems[J]. Proceedings of the CSEE, 2006, 26(20): 98-102.

[8] Billy M T Ho, Henry S H Chung. An Integrated Inverter with Maximum Power Tracking for Grid-Connected PV Systems [ J ] IEEE Transactions on Power Electronics, 2005 (6) : 953-962.

[9] I.-S. Kim, M.-B. Kim, and M.-J. Youn, "New maximum power point tracker using sliding-mode observer for estimation of solar array current in the grid-connected photovoltaic system," IEEE Trans. Ind. Electron.,vol. 53, no. 4, pp. 1027-1035, Jun. 2006.

[10] Yao Zhezhi, Yi Lingzhi, Peng Hanmei, Fu Xi, Deng Dong. Study of Simplified SVPWM Algorithm Based on Three-Level Inverter [C] . 2009 IEEE 6th International Power Electronics and Motion Control Conference.wuhan. May. 2009.

[11] E. Roman, R. Alonso, P. Ibanez, S. Elorduizapatarietxe, and D. Goitia, Intelligent PV module for grid-connected PV systems [ J ] IEEE Trans. Ind. Electron., vol. 53, no. 4, pp. 1066-1073, Jun. 2006.

[12] Nopporn Patcharaprakiti. Maximum power point $t$ racking using adaptive fuzzy logic cont rol for grid-connected photovoltaic system[J ]. Renewable Energy ,2005, 30(3):1771 1788.

[13] Miguel Gon alves Wanzeller, Raimundo Nazareno Cunha Alves, Joao Viana da Fonseca Neto.Current control loop for tracking of maximum power point supplied for photovoltaicnay $[\mathrm{J}]$. IEEE.Transactions on instrumentation and measurement, 2004.53 (4):1304-1310. 